\title{
EDITORIAL
}

\section{How can we minimize barotraumas in our most premature infants?}

Journal of Perinatology (2012) 32, 315-316; doi:10.1038/jp.2012.19

In spite that mechanical ventilation (MV) has many potential side effects, MV is still the preferred initial treatment for infants with respiratory distress syndrome (RDS) and other types of respiratory distress in many neonatal centers. An alternative advantageous treatment for these infants is primary treatment with nasal continuous positive airway pressure (NCPAP), if necessary combined with surfactant treatment by a short-lasting intubation followed by extubation to NCPAP, the so-called INtubation SURfactant Extubation (INSURE) procedure. ${ }^{1-4}$

By using INSURE for RDS, MV and barotraumas can be avoided in many cases, ${ }^{1-3,5,6}$ and as a result, the risk of bronchopulmonary dysplasia (BPD) may be reduced. ${ }^{5-7}$ In a multivariate analysis comparing NCPAP with MV, BPD is simply explained by the incidence of $\mathrm{MV}^{8}$

There are strong indications that surfactant also has a restrictive effect on the development of BPD, although the surfactant introduction has not reduced the incidence of $\mathrm{BPD},{ }^{9,10}$ and $\mathrm{CPAP}$ was significantly more effective in reducing the severity of BPD compared with surfactant treatment in the Support study. ${ }^{11}$ Thus, the incidence of BPD was very low in centers that introduced INSURE compared with centers using MV and rescue surfactant. ${ }^{12}$ An US group reduced the incidence of chronic lung disease in infants with birth weight $<1500 \mathrm{~g}$ by avoiding intubation in the delivery room, adoption of new pulse oximeter limits and very early use of NCPAP and surfactant, ${ }^{13}$ and in a randomized study comparing INSURE with NCPAP, the incidence of BPD, MV and air leaks was less in the INSURE group. ${ }^{7}$ In studies using primary MV, the incidence of BPD was lower following prophylactic surfactant than after rescue treatment with surfactant, ${ }^{14}$ and early selective surfactant treatment reduced the combined mortality and BPD more effectively than the rescue treatment. ${ }^{15}$ Furthermore, surfactant reduced the oxidative stress and the incidence of pneumothorax. ${ }^{14}$ The positive effects of surfactant and INSURE are supported by animal experiments. ${ }^{16,17}$

In newborn lambs, it has been shown that a few large manual inflation impaired the treatment response to surfactant. ${ }^{18}$ This supports the idea that the newborn infants should, if possible, open up their lungs themselves if necessary supported by mask-CPAP in the delivery room.

When CPAP was introduced in the early 70 s, the mortality rate due to RDS was more than halved. ${ }^{19,20}$ This was probably due to a number of positive effects of CPAP. Used as early ventilatory support, one main aim of CPAP is to keep the lungs open, thereby avoiding potentially harmful iterated collapse and re-expansion of terminal air spaces. ${ }^{21,22}$ CPAP may also prevent squeezing of surfactant from the alveoli and excessive consumption. ${ }^{23}$

The INSURE technique allows the infants to be awake and improves the possibility for mother-child attachment and for practicing the kangaroo method, which in itself improves the possibility for breast feeding. NCPAP also requires less sedation than MV and betters the possibility for nursing and observation.

In this issue of Journal of Perinatology, Ramanathan et al. ${ }^{24}$ are publishing a randomized study with the use of a modification of the INSURE method. It includes 110 infants at $<30$ weeks gestation, initially treated and stabilized with NCPAP and subsequently given surfactant (Poractant alfa) combined with MV via endotracheal tube within $60 \mathrm{~min}$. Once stabilized, the infants were extubated to the randomization groups NCPAP or nasal intermittent positive pressure ventilation (NIPPV). The need for MV and BPD was reduced by NIPPV compared with NCPAP, and the conclusion of the study is that the 'modified INSURE' NIPPV in the extubation phase is more effective than NCPAP in improving the infants conditions. As mentioned by the authors, ${ }^{24}$ NIPPV has also been used with success as a primary method of initial treatment for RDS.

In the actual study, ${ }^{24}$ NCPAP was used in the initial phase and MV in an intermittent period. In the delivery room, NCPAP will in most situations be the natural choice of primary treatment. NCPAP may then be replaced with NIPPV in the neonatal intensive care unit if preferred. Another option is to continue with NCPAP and change to treatment with NIPPV if the infant develops frequent apnea or increasing respiratory insufficiency. Analgesic and sedative premedication before intubation for INSURE and in connection with MV is often related to apnea in the extubation phase, and research into the optimal medication is important. Caffeine prophylaxis is recommended. ${ }^{25}$

Ramanathan et $\mathrm{al}^{24}$ speculate that the low use of antenatal steroids might have contributed to the relatively high incidence of BPD in their study population. This is quite possible but a negative effect of antenatal steroids on the development of BPD cannot be excluded. ${ }^{26}$

The ideal treatment of RDS and prevention of BPD is not by using a surfactant, NCPAP, NIPPV or MV, but by a combination of different treatment elements; more clinical studies are needed to find the most optimal combinations suitable for different clinical 
situations. We cannot do without MV but the use of MV especially in the initial phases should be diminished.

\section{Conflict of interest}

The author declares no conflict of interest.

\section{H Verder \\ Department of Pediatrics, Holbaek Hospital, University of Copenhagen, Holbaek, Denmark E-mail: bav@regionsjaelland.dk}

\section{References}

1 Verder H, Robertson B, Greisen G, Ebbesen F, Albertsen P, Lundstrøm K et al. Surfactant therapy and nasal continuous positive airway pressure for newborns with respiratory distress syndrome. $N$ Engl J Med 1994; 331(16): 1051-1055.

2 Verder H, Albertsen P, Ebbesen F, Greisen G, Robertson B, Bertelsen A et al. Nasal continuous positive airway pressure and early surfactant therapy for respiratory distress syndrome in newborns less than 30 weeks's gestation. Pediatrics 1999; 103: e24.

3 Bohlin K, Gudmundsdottir T, Katz-Salamon M, Jonsson B, Blennow M. Implementation of surfactant treatment during continuous positive airway pressure. J Perinatol 2007; 27: 422-427.

4 Sandri F, Plavka R, Ancora G, Simeoni U, Stranak Z, Martinelli S et al. Prophylactic or early surfactant combined with nCPAP in very preterm infants. Pediatrics 2010; 125 e1402-e1409

5 Stevens TP, Blennow M, Meyers EH, Soll RF. Early surfactant administration with brief ventilation vs. selective surfactant and continued mechanical ventilation for preterm infants with or at risk for respiratory distress syndrome. Cochrane Database Syst Rev 2007; 4: CD003063

6 Kribs A, Härtel C, Kattner E, Vochem M, Küster H, Möller J et al. Surfactant without intubation in preterm infants with respiratory distress: first multi-center data. Klin Padiatr 2010; 222: 13-17.

7 Rojas MA, Lozano JM, Rojas MX, Laughon M, Bose CL, Rondon MA et al. Very early surfactant without mandatory ventilation in premature infants treated with early continuous positive airway pressure - A randomized controlled trial. Pediatrics 2009; 123: $137-142$.

8 Van Marter LJ, Allred EN, Pagano M, Sanocka U, Parad R, Moore M et al. Do clinical markers of barotrauma and oxygen toxicity explain interhospital variation in rates of chronic lung disease? The Neonatology Committee for the Developmental Network. Pediatrics 2000; 105: 1194-1201.

9 Engle WA. Surfactant-replacement therapy for respiratory distress in preterm and term neonates. Pediatrics 2008; 121: 419-432.

10 Chong E, Greenspan J, Kirkby S, Culhane J, Dysart K. Changing use of surfactant over 6 years and its relationship to chronic lung disease. Pediatrics 2008; 122: e917-e921.
11 SUPPORT study group of the Eunice Kennedy Shriver NICHD neonatal research network. Early CPAP versus surfactant in extremely preterm infants. $N$ Engl J Med 2010; 362: 1970-1979.

12 Verder H, Bohlin K, Kamper J, Lindwall R, Jonsson B. Nasal CPAP and surfactant for treatment of respiratory distress syndrome and prevention of bronchopulmonary dysplasia. Acta Paediatr 2009; 98: 1400-1408.

13 Birenbaum HJ, Dentry A, Cirelli J, Helou S, Pane MA, Starr K et al. Reduction in the incidence of chronic lung disease in very low birth weight infants: results of a quality improvement process in a tertiary level neonatal intensive care unit. Pediatrics 2009; 123: 44-50.

14 Soll RF, Morley CJ. Prophylactic versus selective use of surfactant in preventing morbidity and mortality in preterm infants. Cochrane Database Syst Rev 2001; 2: CD000510.

15 Soll RF. Early versus delayed selective surfactant treatment for neonatal respiratory distress syndrome. Cochrane Database Syst Rev 1999; 4: CD001456.

16 Bohlin K, Bohaufs RK, Jarstrand C, Curstedt T, Blennow M, Robertson B. Spontaneous breathing or mechanical ventilation alters lung compliance and tissue association of exogenous surfactant in preterm newborn rabbits. Pediatr Res 2005; 57: 624-630.

17 Thomson MA, Yoder BA, Winte VT, Martin H, Catland D, Siler-Kohdr TM et al. Treatment of immature baboons for 28 days with early nasal continuous positive nasal pressure. Am J Respir Crit Care Med 2004; 169: 1054-1062.

18 Björklund LJ, Ingimarsson J, Curstedt T, John J, Robertson B, Werner 0 et al. Manual ventilation with a few large breaths at birth compromises the therapeutic effect of subsequent surfactant replacement in immature lambs. Pediatr Res 1997; 42 348-355.

19 Rhodes PG, Hall RT. Continuous positive airway pressure delivered by face mask in infants with idiopathic respiratory distress syndrome: a controlled study. Pediatrics 1973; 52: 17-21

20 Dunn PM. Respiratory distress syndrome. Continuous positive airway pressure (CPAP) using the Gregory box. Proc R Soc Med 1984; 67: 245-247.

21 Lachmann B. Opeb up the lung and keep the lung open. Intensive Care Med 1992; 18: $319-321$.

22 Jonson B. Ventilation patterns, surfactant and lung injury. Biol Neonate 1997; 71(suppl 1): 13-17.

23 Bos J, Lachmann B. Surfactant function: is it influenced by artificial ventilation? In: Cosmi EV (eds). The Surfactant System of the Lung: Prevention and Treatment of Neonatal and Adult Respiratory Distress Syndrome. MacMillan Press: London, England, 1991; 96-106.

24 Ramanathan R, Sekar CK, Rasmussen M, Bhatia J, Soll RF. Nasal intermittent positive pressure ventilation after surfactant treatment for respiratory distress syndrome in preterm infants <30 weeks' gestation: a randomized, controlled trial. J Perinatol 2012 (this issue)

25 Schmidt B, Roberts RS, Davis P, Doyle LW, Barrington KJ, Ohlsson A et al. Evidencebased neonatal drug therapy for prevention of bronchopulmonary dysplasia in very-low-birth-weight infants. Neonatology 2008; 93: 284-287.

26 Jobe A. Antenatal factors and the development of Bronchopulmonary dysplasia. Semin Neonatol 2003; 8: 9-17. 